\title{
GÊNERO, ETNIA E RAÇA: DÉBITO OU CRÉDITO NA CONTABILIDADE?
}

\author{
José Luiz Borsatto Junior 1 \\ Evellyn Danielly Zabotti 2 \\ Maria da Piedade Araújo ${ }^{3}$
}

- Artigo recebido em: 07/08/2018 -• Artigo aceito em: 05/02/2020 -.- Segunda versão aceita em: 01/05/2020

\section{RESUMO}

Esta pesquisa tem por objetivo verificar se existe discriminação por gênero e étnico-racial na remuneração de contadores, em cada região geográfica do Brasil. Dados sobre a remuneração dos contadores, oriundos dos microdados da Relação Anual de Informações Sociais de 2014, foram analisados com o uso de estatística descritiva e modelagem econométrica. Para representar cada região, os seguintes estados foram selecionados para esta pesquisa: Amazonas, Bahia, Mato Grosso, Paraná e São Paulo. Assim, buscou-se explicar o comportamento das remunerações dos contadores por meio das variáveis explicativas: tempo de trabalho, porte de empresa, sexo, cor de pele e grau de instrução. Os principais resultados confirmam a presença de discriminação salarial em função de sexo biológico para as mulheres e em função de cor de pele para os contadores autodeclarados como não brancos. A discriminação por sexo biológico reduz, em média, 28,83\% a remuneração das contadoras mulheres. A discriminação por cor de pele reduz a remuneração de homens e mulheres e a combinação cor de pele e sexo feminino deprecia o salário das contadoras autodeclaradas como não brancas, em média, em 45,19\%. Conclui-se que a discriminação salarial por gênero e étnico-racial se faz presente na profissão contábil. Salienta-se que tal situação das mulheres negras e pardas se agrava, ou seja, a discriminação é ainda maior. Diante desse balanço salarial da profissão contábil, as contas gênero, etnia e raça possuem natureza devedora e os saldos destas contas indicam prejuízo acumulado.

Palavras-Chave: Gênero. Etnia. Raça. Contabilidade. Discriminação salarial.

\footnotetext{
1 Mestre em Contabilidade pela Universidade Estadual do Oeste do Paraná (UNIOESTE). Endereço: Rua Maria Ignácia da Silva, 3064, Parque San Remo I, 87.506-300, Umuarama-PR. Email: junior.borsatto@yahoo.com.br https://orcid.org/0000-0002-2463-6500

2 Mestra em Contabilidade pela Universidade Estadual do Oeste do Paraná (UNIOESTE). Endereço: Rua Universitária, 1619, Universitário, 85.819-110, Cascavel-PR. E-mail: evellyndz@gmail.com https://orcid.org/0000-0002-9842-7197

3 Doutora em Economia Aplicada pela Universidade de São Paulo (ESALQ-USP). Programa de Pós-Graduação em Contabilidade, Universidade Estadual do Oeste do Paraná. Endereço: Rua Universitária, 1619, Universitário, 85.819-110, Cascavel-PR. E-mail: madadepi@gmail.com https://orcid.org/0000-0002-8111-897X
}

Editora responsável pela aprovação do artigo: $\mathrm{Dr}^{\mathrm{a}}$. Bruna Camargos Avelino Editora responsável pela edição do artigo: $\mathrm{Dr}^{\mathrm{a}}$. Bruna Camargos Avelino 


\title{
GENDER, ETHNICITY AND RACE: DEBIT OR CREDIT ON ACCOUNTING?
}

\begin{abstract}
This research aims to verify whether gender and ethnic-racial discrimination exist in the remuneration of accountants in each geographical region of Brazil. Accountants' remuneration data, extracted from the microdata of the Annual Social Information Report of 2014, were analyzed using descriptive statistics and econometric modeling. To represent each region, the following states were selected for this research: Amazonas, Bahia, Mato Grosso, Paraná and São Paulo. Thus, we attempted to explain the behavior of the accountants' remuneration by the following explanatory variables: work time, company size, gender, skin color and education level. The main results confirm the presence of biological sex wage discrimination for women and skin color wage discrimination for self-declared accountants as non-whites. Discrimination by gender reduces, on average, $28.83 \%$ the remuneration of women accountants. Discrimination by skin color reduces the pay of men and women, and the combination of skin color and female sex depreciates the salary of self-declared accountants as non-white, on average, $45.19 \%$. It is concluded that wage discrimination by gender and ethno-racial is present in the accounting profession. It should be noted that this situation of black and brown women is aggravated, that is, the discrimination is even greater. Given this salary balance of the accounting profession, the accounts gender, ethnicity and race have debit balance and the balances of these accounts indicate accumulated loss.
\end{abstract}

Keywords: Gender. Ethnicity. Race. Accounting. Wage discrimination.

\section{INTRODUÇÃO}

Dentre os estruturantes da desigualdade social brasileira, gênero e raça são fatores relacionados ao agravamento das condições de precariedade e exclusão de grande parcela da população brasileira (Instituto de Pesquisa Econômica Aplicada [IPEA], 2009). No que diz respeito ao mercado de trabalho, há uma hierarquia estanque de privilégios, organizada do maior para o menor rendimento, na qual o topo é ocupado pelos homens brancos, seguidos por mulheres brancas, homens negros e mulheres negras na base dessa hierarquia. Conforme dados do IPEA (2015), as distâncias entre esses grupos não se alteram expressivamente ao longo do período de vinte anos.

A Contabilidade, sob a ótica sociológica, conecta-se a esse cenário de desigualdade, decorrente dos contextos social e histórico. Os valores sociais, organizacionais e as formas de atuação da contabilidade influenciam o ambiente e por ele são influenciados (Miller, 1994). A partir dessa perspectiva, é possível analisar a profissão contábil como incorporadora e reprodutora de práticas discriminatórias.

No entanto, estudos em contabilidade sobre gênero, etnia e raça são relativamente incipientes e sinalizam a existência de desigualdade na profissão contábil. No cenário internacional, a discriminação de contadoras mulheres e de diversos grupos étnicos permeia o meio profissional contábil em países colonizados pelo Império Britânico foi abordada por Hammond (2003). Fearfull e 
Kamenou (2006) investigaram o motivo de empresas perpetuarem as dificuldades de aceitação corporativa e progressão de mulheres pertencentes à minoria étnicas em organizações que possuem políticas de combate às discriminações. Duff (2011) identificou práticas discriminatórias e excludentes na representação de homens e mulheres, brancos e negros, nos relatórios anuais de grandes firmas de auditoria do Reino Unido. O exercício profissional da contabilidade no Canadá reproduz fatores discriminantes nas interações sociais; homens brancos de ascendência britânica desfrutam de privilégios que dificultam o avanço profissional de contabilistas que não pertencem a esse grupo (Thomson \& Jones, 2016).

No âmbito nacional, os estudos dessa natureza são escassos e introdutórios. No contexto paranaense da profissão, os resultados da pesquisa de Altoé (2014) sugerem que os cargos mais baixos na hierarquia organizacional são ocupados principalmente por mulheres, o que conferem a tais profissionais remunerações inferiores aos seus pares homens, que atuam em cargos mais elevados. Situação semelhante foi identificada por Brighenti, Jacomossi e Silva (2015) ao investigarem contadores e auditores de Santa Catarina. Conforme os autores, salários menores são atribuídos às mulheres, ainda que atributos como idade, tempo de emprego, formação e tamanho da empresa sejam similares entre homens e mulheres.

Consequentemente, observa-se na literatura situações de desigualdades relacionadas a gênero, etnias e raça, no âmbito profissional da contabilidade de diversos países, inclusive no Brasil. Em complemento, um panorama geral hierarquizado do mercado brasileiro é pode ser identificado a partir dos dados do IPEA (2015). Com base nessa conjuntura, torna-se oportuna a investigação sobre como essas desigualdades se traduzem em discriminação salarial no contexto da profissão contábil, em âmbito nacional.

Considerando-se tais ponderações, a representatividade da participação de mulheres na profissão contábil, e a diversidade étnico-racial que caracteriza o Brasil, pergunta-se: existe discriminação salarial entre contadores brasileiros em função de gênero e aspectos étnico-raciais? Com o propósito de responder a esta questão, o objetivo central deste estudo consiste em verificar se existe discriminação por gênero e étnico-racial na remuneração de contadores, por região do país. Os objetivos específicos são: a) descrever a configuração da profissão contábil em termos demográficos, a saber: sexo, remuneração, tempo de trabalho e porte da empresa e, b) avaliar estatisticamente a relação da composição salarial com as variáveis tempo de trabalho, porte de empresa, sexo, cor de pele e grau de instrução.

Em se tratando do contexto nacional, há uma lacuna de pesquisas sobre a temática ora investigada na literatura. Apenas Silva (2016), em sua tese, contextualiza a interseccionalidade entre gênero e raça e a profissão contábil. A autora "coloca em xeque" a propagação do mito da democracia racial ao investigar as barreiras de ascensão profissional que as mulheres do meio contábil, especialmente mulheres negras, enfrentam. Os resultados da pesquisa indicam barreiras específicas a serem transpostas. Pesquisas com essa configuração remetem à transformação social. Portanto, em conformidade com Silva (2016), entende-se a relevância da propagação de estudos dessa natureza. Deste modo, como contribuição teórica, este estudo visa expandir o corpus de conhecimento nacional sobre a temática gênero, etnia e raça, voltada para a contabilidade.

70 Revista Contabilidade Vista \& Revista, ISSN 0103-734X, Universidade Federal de Minas Gerais, Belo Horizonte, v. 31, n. 2, p. 68-94, maio/ago. 2020 
Observa-se como lacuna de pesquisa também a forma como a remuneração de contadores foi estudada, priorizando-se, apenas, questões que envolvem o gênero desses profissionais, com alcance geográfico limitado a um estado da federação (Brighenti, Jacomossi \& Silva, 2015). Nesse sentido, utilizouse modelo econométrico, considerando-se aspectos que envolvem gênero, etnia e raça. Ademais, os fatores tempo de empresa, nível de instrução e porte empresarial também constam no modelo, de modo que a contribuição empírica do estudo consiste na predição de valores estimados de contadores com bases em tais aspectos, para todas as regiões geográficas do Brasil.

As contribuições sociais consistem na evidenciação de atributos quantitativos e qualitativos da remuneração de contadores e na identificação de aspectos sociais discriminatórios na remuneração de contadores em função de gênero, etnia e raça, especialmente porque se trata de uma profissão regulamentada.

Além desta introdução, este artigo possui outras quatro seções. A segunda seção consiste na fundamentação teórica sobre a temática proposta. $\mathrm{Na}$ sequência, tem-se o delineamento metodológico. A análise e discussão dos dados encontram-se na quarta seção. Por último, apresentam-se as considerações finais, o balanço com os respectivos saldos das contas contábeis de gênero e de raça.

\section{GÊNERO, ETNIA E RAÇA NA PROFISSÃO CONTÁBIL}

A utilização equivocada dos conceitos de sexo e gênero é frequente. Sexo refere-se a um aspecto biológico dos seres humanos, ao passo que gênero é visto como uma construção histórica que atribui significados e poder aos sexos, de acordo com as relações sociais de uma época (Souza \& Carrieri, 2010). Especificamente, "gênero é uma categorização social imposta sobre um corpo sexuado" (Scott, 1995, p. 6).

Em uma lógica binária do masculino versus feminino, admite-se a existência de um polo que será desvalorizado, designado como minoria, o qual poderá ser tolerado pela sociedade (Souza \& Carrieri, 2010). A incorporação social do masculino e do feminino associados a homens e a mulheres, respectivamente, ocorre por meio de diferentes mecanismos endossados por instituições da sociedade (Medeiros \& Valadão, 2011), dentre as quais se têm as organizações.

Os contextos cultural e histórico são inerentes às organizações, e possibilitam a diferenciação entre os papéis sociais atribuídos a homens e mulheres, pois estão arraigados à concepção de divisão sexual do trabalho, em que alguns deveres e ocupações são reconhecidos basicamente como masculinas e outros como femininas. As organizações são uma arena em que as imagens culturais amplamente disseminadas de gênero são criadas e repetidas (Acker, 1990).

Uma das características mais evidentes do mercado de trabalho brasileiro é o diferencial salarial entre gêneros, etnias e raças, sendo a discriminação um dos componentes relevantes na explicação dessa diferença (Cambota \& Pontes, 2004). Conforme os autores, a discriminação pode ocorrer de duas maneiras: por meio da discriminação salarial ou por segregação ocupacional. A primeira ocorre quando indivíduos igualmente produtivos, alocados nos mesmos postos de 
trabalho, recebem rendimentos distintos. Já, a segregação ocupacional, ocorre quando trabalhadores igualmente produtivos têm chances diferentes de ocupar empregos de maior remuneração, fenômeno denominado teto de vidro, glass ceiling no original (Steil, 1997).

Especificamente na profissão contábil, conforme investigado por Altoé (2014), quanto mais baixo o nível hierárquico, maior é a atuação da mulher. Além disso, a autora argumenta que os maiores salários são auferidos por homens, enquanto que as faixas salariais iniciais são ocupadas principalmente por profissionais do sexo feminino.

Brighenti, Jacomossi e Silva (2015) investigaram o mercado de trabalho catarinense e sugerem que, mesmo com pouca diferença na escolaridade entre homens e mulheres, os contadores e auditores do sexo masculino recebem uma remuneração significativamente superior aos seus pares do sexo feminino. Quanto aos fatores influentes na remuneração, os atributos faixa etária, tempo de emprego, escolaridade e porte de empresa provaram-se similares para homens e mulheres, não justificando as diferenças nas remunerações desses profissionais.

Embora a literatura, de modo geral, relate as experiências das mulheres grupo que experiência as desigualdades de uma forma maior e que ainda precisa se emancipar -, Haynes (2008) ressalta que os homens também experimentam privação social e econômica, violência e exploração sob o capitalismo global. Os homens são igualmente submetidos aos desafios dentro da profissão contábil de longas horas de trabalho, culturas masculinas, parentalidade, identidade masculina, heteronormatividade e experiências de identidades interseccionais.

No que tange aos aspectos étnico-raciais, Bonilla-Silva (1999) concluíram que em pesquisas de tal natureza faz-se necessário visualizar o processo histórico de racialização. Assim, a miscigenação entre povos de matrizes variadas que compõem a população nacional torna-se um elemento relevante ao se falar de raça e conflitos étnicos, principalmente em países com ampla diversidade cultural como o Brasil, conforme destaca Rosa (2014).

O termo etnia tem um conceito amplo que envolve um conjunto de elementos comuns entre indivíduos, tais como raça, idioma, território e noção de pertencimento (Conceição, 2009), sendo este último determinante para a configuração de um grupo étnico. Assim, a etnicidade é usualmente associada a aspectos culturais (Anisette, 2003). Por sua vez, a palavra raça "remete simbolicamente a uma origem comum, evidenciando a continuidade das descendências, o parentesco pelo sangue, a hereditariedade das características fisiológicas, psicológicas e sociais" (Conceição, 2009, p. 3).

Todavia, Nogueira (2017) compara os contextos dos Estados Unidos da América (EUA) e do Brasil e indica a existência de diversas concepções de raça e etnia, o que viabiliza conceitos distintos de preconceito racial. Nos EUA, O indivíduo sofre as consequências do preconceito racial a partir da suposição de que é descendente de um determinado grupo étnico. Já no Brasil, o preconceito racial é exercido em relação à aparência racial, os traços físicos do indivíduo. Preconceito "de origem" e "de marca", respectivamente (Nogueira, 2007, p. 291 292). 
Diante dessas duas perspectivas, entende-se que raça é um conceito socialmente construído, analogamente às concepções de classes sociais e gênero (Bonilla-Silva, 1997). Trata-se de uma questão que vai além do determinismo biológico e da concepção antropológica de raças superiores dominando raças inferiores (Anisette \& Prasad, 2017). Entretanto, Silva (2016) lembra que o entendimento de raça como característica genética permanece forte no imaginário popular, ainda que não existam diferentes raças entre os seres humanos.

Anisette e Prasad (2017) entendem que o preconceito racial é uma construção social e decorre de manifestações culturais, inerentes às relações sociais, que geram efeitos diferenciadores sobre sujeitos conforme a categoria racial percebida que eles ocupam. Agrupar os indivíduos por raça, algo típico na sociedade, de modo geral, produz hierarquização desses mesmos indivíduos, definida por meio das relações sociais entre as raças (Bonilla-Silva, 1997). Isto é, esta hierarquização produz a noção de raças superiores e inferiores; o discurso de "nós" e "eles" permite a subordinação de raças. Para ilustrar essa situação de diferenciação racial no âmbito da profissão contábil, algumas pesquisas destacam-se: Hammond e Streeter (1994) mostraram as desigualdades raciais que privaram os contadores negros americanos de equidade nas oportunidades profissionais. A história dos primeiros contadores negros certificados profissionalmente na África do Sul é contada na pesquisa de Hammond, Clayton e Arnold (2012); os autores revelam uma versão diferente da "história oficial" difundida pela categoria profissional, permeada de tratamento discriminatório.

A dicotomia brancos-negros é simplificadora de uma realidade ainda mais complexa (Kim, 2004). Anisette (2003) investigou, em Trinidad e Tobago, o contexto de exclusão e sub-representação que a maioria étnica não branca enfrentou em tal país - cerca de $80 \%$ da população -, diante da hegemonia britânica - branca e imigrante-colonizadora. Os resultados dessa pesquisa indicam que as barreiras impostas pelas regras de registro profissional marginalizavam os nativos e profissionais de outras etnias em detrimento dos contadores expatriados britânicos.

Situação similar foi identificada por Kim (2004), ao investigar a minoria composta por contadores chineses em exercício profissional na Nova Zelândia, e por Thomson e Jones (2006), ao desenvolverem estudo sobre a situação experienciada por contadores imigrantes no Canadá. O conceito de desigualdade racial é oriundo das relações sociais. Desse modo, em sistemas sociais racializados como o Brasil, privilegia-se a raça tida como superior e barreiras são criadas aos grupos considerados inferiores (Bonilla-Silva, 1999), situação identificada na pesquisa do IPEA (2015).

Diante das desigualdades relativas a gênero e étnico-raciais verificadas nas pesquisas citadas anteriormente, os achados do estudo de Guimarães (2002) e Hirata (2014) indicam a inclusão de raça, além de gênero, para explicar as desigualdades salariais. Os resultados ampliam a percepção sob as diferenças entre homens e mulheres, para diferenças entre homens brancos e negros e mulheres brancas e negras. De maneira similar, Anisette (2003) preconiza que raça, gênero e classe compõem a tríade da desigualdade social e são essenciais para a investigação da desigualdade no campo contábil. 
A abordagem teórica transdisciplinar, que integra a complexidade das identidades e das desigualdades sociais por intermédio de um enfoque integrado das categorias de sexo/gênero, classe, raça, etnicidade, idade, deficiência e orientação sexual, é a teoria da interseccionalidade (Hirata, 2014).

A interseccionalidade considera as múltiplas fontes da identidade, e não tem a pretensão de propor uma nova teoria globalizante da identidade (Hirata, 2014). O enfoque interseccional reconhece a multiplicidade dos sistemas de opressão que opera a partir de gênero, classe, raça, mas também postula sua interação na produção e reprodução das desigualdades sociais (Hirata, 2014).

Nesse contexto, como plataforma teórica, optou-se pela teoria da interseccionalidade, uma vez que o interesse teórico e epistemológico deste estudo, é a articulação das variáveis gênero e raça, para a verificação da existência de discriminação por gênero e étnico-racial na remuneração de contadores, especificamente, entre contadores homens brancos e negros e contadoras mulheres brancas e negras.

\section{DELINEAMENTO METODOLÓGICO}

Em resposta à problematização apresentada, o objetivo deste estudo é de caráter descritivo (Hair, Babin, Money \& Samovel, 2005). Para tal, adotaram-se estatística descritiva e modelagem econométrica como estratégias de pesquisa. Assim, abordou-se o problema de pesquisa quantitativamente (Hair et al., 2005).

O universo investigado é composto por contadores de todas as regiões geográficas do Brasil. Elencaram-se os estados do Amazonas, da Bahia, de Mato Grosso, do Paraná e de São Paulo como representantes de cada região. Tal seleção se deu conforme o maior Produto Interno Bruto (PIB) estadual, ou seja, o critério de seleção foi a maior participação, em termos de geração de riqueza, na economia nacional. Para o Centro-Oeste, o estado de Mato Grosso foi escolhido em vez do Distrito Federal (DF), este último possuidor do maior PIB da região. Isto se justifica devido às particularidades geográficas e econômicas do DF.

Após a seleção dos estados que compõem a população do estudo, buscou-se nos microdados da Relação Anual de Informações Sociais (RAIS) O Código Brasileiro de Ocupações (CBO) dos contadores, qual seja, o CBO 2522-10. Analisaram-se os dados do ano de 2014, a última série de dados divulgada. $O$ resultado da seleção dos contadores encontra-se na Tabela 1. 
Tabela 1

Composição da população

\begin{tabular}{|c|c|c|c|c|c|}
\hline Região & Estado & $\begin{array}{l}\text { Total de } \\
\text { Contadores }\end{array}$ & $\begin{array}{l}\text { Indivíduos } \\
\text { excluídos }\end{array}$ & $\begin{array}{c}\text { Tamanho } \\
\text { da seleção } \\
\text { (n.) }\end{array}$ & $\begin{array}{l}\text { Tamanho da } \\
\text { seleção (\%) }\end{array}$ \\
\hline Norte & Amazonas & 2.234 & 1.102 & 1.132 & 50,67 \\
\hline Nordeste & Bahia & 4.941 & 2.089 & 2.852 & 57,72 \\
\hline $\begin{array}{l}\text { Centro- } \\
\text { Oeste }\end{array}$ & $\begin{array}{l}\text { Mato } \\
\text { Grosso }\end{array}$ & 2.630 & 1.096 & 1.534 & 58,33 \\
\hline Sudeste & São Paulo & 68.307 & 23.845 & 44.462 & 65,09 \\
\hline Sul & Paraná & 10.607 & 4.213 & 6.394 & 60,28 \\
\hline Total & & 88.719 & 32.345 & 56.374 & 63,54 \\
\hline
\end{tabular}

Fonte: Microdados RAIS (2014).

O processo de seleção dos profissionais ocorreu em três etapas. Primeiramente, buscou-se pelo CBO 2522-10 na base de dados, o que resultou em um total de 88.719 contadores. Em segundo lugar, excluiu-se 32.345 outliers, pelos motivos que seguem: profissionais com o ensino superior incompleto em 2014, ausência de preenchimento de informações necessárias para o estudo (remuneração, cor de pele e instrução não declaradas), remunerações discrepantes (inferiores ao salário mínimo da época, por se tratarem de pessoas que trabalhavam em tempo parcial, ou remunerações demasiadamente altas) que influenciavam os resultados do modelo, e remoção de alguns profissionais doutores, pela baixa representatividade nas regressões (fato especificado adiante, na Tabela 2). Por fim, procedeu-se à seleção dos profissionais, conforme a quinta coluna da Tabela 1.

A primeira etapa da análise dos dados foi executada com o uso de estatística descritiva, a fim de se descrever a configuração da profissão contábil em termos demográficos, a saber: sexo, remuneração, tempo de trabalho, e porte da empresa; primeiro objetivo específico deste estudo.

O construto interseccionalidade (Hirata, 2014), representa as variáveis conceituais gênero, etnia e raça. Para operacionalização desse construto teórico, as variáveis observáveis do modelo são, sexo biológico para gênero e cor de pele para etnia e raça. Adicionalmente, utilizou-se as variáveis observáveis porte de empresa, tempo de serviço e instrução para a identificação de aspectos situacionais relativos à população. Enfatiza-se que as variáveis observáveis correspondem às nomenclaturas adotadas constantes no layout da RAIS.

Convém destacar, que se trabalhou com variáveis binárias para captar efeitos qualitativos, tais como sexo e cor da pele. Por exemplo, a primeira hipótese testa se o efeito qualitativo existe. Se o coeficiente associado a tal variável binária for estatisticamente significativo, é porque existe a discriminação para a população em questão. Ao se assumir que a observação para o sexo masculino e cor branca será 1, espera-se sinal positivo para tais parâmetros, significando discriminação em favor do indivíduo do sexo masculino e declarados da cor branca.

Para segunda etapa da análise dos dados, segundo objetivo específico da pesquisa, utilizou-se o método de Mínimos Quadrados Ordinários, que permite obter estimativas lineares não tendenciosas e de variância mínima para os 
parâmetros da equação de regressão, para se testar as hipóteses de pesquisa. A reta de regressão a ser ajustada é dada pela Equação 1.

Equação 1

Remuneraçãoi $=a+\beta_{2}$ tempo $+\beta_{3}$ tamanho $+\beta_{4}$ Dummy_sexo + $\beta_{5}$ Dummy_cor_pele $+\beta_{6}$ Dummy_instrução $+\varepsilon_{i}$

Em que:

Remuneração refere-se à remuneração mensal média dos contadores em reais; Tempo refere-se ao tempo de trabalho na empresa atual, em meses; Tamanho refere-se ao porte da empresa, conforme a classificação da RAIS;

Dummy_sexo refere-se à variável binária sexo, sendo (1) para o sexo masculino e (0) para o sexo feminino, sob o pressuposto de que homens têm salários mais altos; Dummy_cor_pele refere-se às variáveis binárias e binária de categorização cor de pele; a especificação de tais variáveis encontram-se na Tabela 2;

Dummy_instrução refere-se às variáveis binárias e binária de categorização nível de instrução; a especificação de tais variáveis encontram-se na Tabela 2;

$a, \beta_{2}, \beta_{3}, \beta_{4}, \beta_{5}$ e $\beta_{6}$, são os parâmetros a serem estimados pela regressão;

$\varepsilon$ é o erro aleatório que tem média zero, variância constante e covariância entre pares de erros distintos iguais a zero;

O subscrito i refere-se às unidades cross-sections (profissionais de contabilidade);

Devido às particularidades dos dados, relativas às diversidades de cada estado, e com o intuito de analisar a seleção de contadores de modo mais diversificado possível em termos de cor de pele e formação, a Equação 1 consiste no modelo genérico, o qual foi personalizado conforme os dados de cada unidade federativa. Assim, parte do modelo é formado por binárias de categorias.

As variáveis dummy por serem artificiais para representarem aspectos qualitativos, assumem valor 0 ou 1. Deste modo, nas variáveis dummy de categoria, quando uma determinada observação possuir o atributo (por exemplo, nível superior completo) receberá o valor 1 e todas as demais receberão 0. Desta maneira, a soma dos vetores das variáveis de categoria deve ser 1. Para que o modelo seja rodado com o termo constante e não apresente problema de multicolinearidade exata, exclui-se uma das categorias, que servirá de referência. Assim sendo, excluiu-se a binária do extremo inferior. A especificação das binárias de categoria pode ser visualizada na Tabela 2. 


\section{Tabela 2}

Especificação das binárias de categorização do modelo genérico

\begin{tabular}{|c|c|c|}
\hline UF & $\begin{array}{lll}\text { Categorias } & - & \text { variável } \\
\text { Dummy_cor_pele } & & \\
\end{array}$ & Categorias - variável Dummy_instrução \\
\hline AM & $\begin{array}{l}\text { Sem categorias, (1) para pardos e (0) } \\
\text { para não pardos, sob o pressuposto } \\
\text { de que os não pardos têm salário mais } \\
\text { alto. }\end{array}$ & $\begin{array}{l}\text { Com categorias, (1) para graduados, (2) } \\
\text { para mestres e (3) para doutores, sob o } \\
\text { pressuposto de que os com título de doutor } \\
\text { têm salário mais alto. }\end{array}$ \\
\hline BA & $\begin{array}{l}\text { Com categorias, (1) para pardos, (2) } \\
\text { para brancos e ( } 3 \text { ) para os demais, } \\
\text { sob o pressuposto de que os brancos } \\
\text { têm salário mais alto. }\end{array}$ & $\begin{array}{l}\text { Sem categorias, (1) para graduados, (0) } \\
\text { para mestres, sob o pressuposto de que os } \\
\text { com título de mestre têm salário mais alto. }\end{array}$ \\
\hline MT & $\begin{array}{l}\text { Com categorias, (1) para brancos, (2) } \\
\text { para pardos e (3) para os demais, sob } \\
\text { o pressuposto de que os brancos têm } \\
\text { salário mais alto. }\end{array}$ & $\begin{array}{l}\text { Sem categorias, (1) para graduados, (0) } \\
\text { para mestres, sob o pressuposto de que os } \\
\text { com título de mestre têm salário mais alto. }\end{array}$ \\
\hline SP & $\begin{array}{l}\text { Sem categorias, (1) para brancos e (0) } \\
\text { para não brancos, sob o pressuposto } \\
\text { de que os não pardos têm salário mais } \\
\text { alto. }\end{array}$ & $\begin{array}{l}\text { Sem categorias, (1) para graduados, (0) } \\
\text { para os demais, sob o pressuposto de que os } \\
\text { demais têm salário mais alto, pois agregam } \\
\text { mestres e doutores. }\end{array}$ \\
\hline PR & $\begin{array}{l}\text { Sem categorias, (1) para brancos e (0) } \\
\text { para não brancos, sob o pressuposto } \\
\text { de que os não pardos têm salário mais } \\
\text { alto. }\end{array}$ & $\begin{array}{l}\text { Sem categorias, (1) para graduados, (0) } \\
\text { para os demais, sob o pressuposto de que os } \\
\text { demais têm salário mais alto, pois agregam } \\
\text { mestres e doutores. }\end{array}$ \\
\hline
\end{tabular}

Fonte: Elaborada pelos autores.

O vetor cor de pele é composto por variável binária simples para as unidades federativas AM, SP e PR, conforme a predominância de pessoas que se declararam pardas (AM) ou brancas (PR e SP) - tais estados apresentaram a população de contadores concentrados principalmente entre brancos e pardos, ou vice-versa. Já nos estados da Bahia e do Mato Grosso, a categorização foi necessária, conforme a Tabela 2, devido ao equilíbrio maior entre as quantidades de pessoas que se declararam pardos, brancos e outros (categoria que inclui os que declararam a cor da pele como indígena, preta ou amarela), com o objetivo de se obter maior representatividade e para ser melhor captado pelo modelo.

O vetor instrução assumiu o formato de categorização apenas para o Estado do Amazonas, para a distinção de graduados, mestres e doutores (Tabela 2). Adotaram-se binárias simples para os demais estados, entretanto, os doutores foram excluídos das seleções da Bahia e do Mato Grosso, pois as remunerações de tais profissionais distorceram os resultados obtidos nos testes iniciais de suas regressões.

Considerando os objetivos propostos e os resultados de pesquisas já relatadas anteriormente, estabeleceram-se as seguintes hipóteses de pesquisa:

Hipótese $1\left(H_{1}\right)$ : contadores do sexo masculino têm mais chances de auferirem salário maior do que contadoras;

Hipótese $2\left(\mathrm{H}_{2}\right)$ : existe discriminação salarial devido à cor da pele em favor do sujeito declarado da cor "branca".

O software utilizado para estimar os parâmetros do modelo e efetuar todos os testes de consistência foi o EViews $7^{\circledR}$. Esta pesquisa delimita-se aos estados selecionados como representantes das regiões geográficas do país. Como limitação de pesquisa salienta-se a impossibilidade de se investigar a inserção dos 
profissionais na hierarquia organizacional, haja vista tais informações não integram o preenchimento da RAIS.

\section{ANÁLISE E DISCUSSÃO DOS RESULTADOS}

\subsection{Demografia da Profissão Contábil nos Estados Selecionados}

A Tabela 3 caracteriza a composição da população de contadores analisada, em termos de sexo. Apenas no Paraná o número de contadores do sexo masculino $(52,11 \%)$ supera a quantidade de contadoras do sexo feminino, que representa $47,89 \%$ do total de profissionais.

\section{Tabela 3}

Contadores por estado e sexo

\begin{tabular}{cccccccccccc}
\hline \multirow{2}{*}{ Sexo } & \multicolumn{2}{c}{ Amazonas } & \multicolumn{2}{c}{ Bahia } & \multicolumn{2}{c}{ Mato Grosso } & \multicolumn{2}{c}{ Paraná } & \multicolumn{2}{c}{ São Paulo } \\
\cline { 2 - 12 } & $\mathbf{Q}$ & $\mathbf{\%}$ & $\mathbf{Q}$ & $\mathbf{\%}$ & $\mathbf{Q}$ & $\mathbf{\%}$ & $\mathbf{Q}$ & $\mathbf{\%}$ & $\mathbf{Q}$ & $\mathbf{\%}$ \\
\hline Masculino & 438 & 38,69 & 1.411 & 49,47 & 692 & 45,11 & 3.332 & 52,11 & 21.89 & 49,25 \\
& & & & & & & & & 6 & \\
\hline Feminino & 694 & 61,31 & 1.441 & 50,53 & 842 & 54,89 & 3.062 & 47,89 & 22.56 & 50,75 \\
& & & & & & & & & $\mathbf{6}$ & \\
\hline Total & $\mathbf{1 . 1 3}$ & $\mathbf{1 0 0 , 0}$ & $\mathbf{2 . 8 5 2}$ & $\mathbf{1 0 0 , 0}$ & $\mathbf{1 . 5 3 4}$ & $\mathbf{1 0 0 , 0}$ & $\mathbf{6 . 3 9 4}$ & $\mathbf{1 0 0 , 0}$ & $\mathbf{4 4 . 4 6}$ & $\mathbf{1 0 0 , 0}$ \\
& $\mathbf{2}$ & $\mathbf{0}$ & & $\mathbf{0}$ & & $\mathbf{0}$ & & $\mathbf{0}$ & $\mathbf{2}$ & $\mathbf{0}$ \\
\hline
\end{tabular}

Fonte: Baseada nos Microdados RAIS (2014).

Percebe-se que, mesmo com maior representatividade do sexo feminino, a quantidade dessas profissionais gira em torno de 50 a $55 \%$ do total nos estados da Bahia, Mato Grosso e São Paulo, ou seja, há um certo equilíbrio em tais estados. Apenas no estado do Amazonas existe uma diferença destacada, em que $61,31 \%$ dos contadores são mulheres.

Embora contadoras comporem a maior parte da população analisada, a Tabela 4 revela que a remuneração mensal das profissionais do sexo feminino é inferior à remuneração auferida pelos profissionais do sexo masculino, ainda que o tempo de trabalho na mesma empresa seja similar em termos médios. O estado de São Paulo possui o maior distanciamento entre as médias salariais, comparando-se os profissionais dos sexos masculino e feminino. 
Gênero, Etnia e Raça: Débito ou Crédito a Contabilidade?

\section{Tabela 4}

Remuneração (em $\mathrm{R} \$$ mil) e tempo de trabalho por sexo e estado

\begin{tabular}{|c|c|c|c|c|c|c|c|c|c|c|c|}
\hline \multirow{2}{*}{\multicolumn{2}{|c|}{ Variáveis }} & \multicolumn{2}{|c|}{ Amazonas } & \multicolumn{2}{|c|}{ Bahia } & \multicolumn{2}{|c|}{ Mato Grosso } & \multicolumn{2}{|c|}{ Paraná } & \multicolumn{2}{|c|}{ São Paulo } \\
\hline & & $M^{a}$ & $\mathrm{Fb}$ & $M$ & $\mathbf{F}$ & $M$ & $F$ & $M$ & $\mathbf{F}$ & $M$ & $\mathbf{F}$ \\
\hline \multirow{5}{*}{$\begin{array}{c}\text { Remu- } \\
\text { neração } \\
\text { mensal } \\
\text { (média) }\end{array}$} & Mín. & 0,72 & 0,36 & 0,72 & 0,72 & 0,72 & 0,72 & 0,72 & 0,72 & 0,22 & 0,22 \\
\hline & Méd & 5,80 & 4,23 & 5,94 & 4,26 & 5,02 & 3,38 & 5,40 & 4,14 & 7,23 & 5,30 \\
\hline & Med & 4,45 & 3,45 & 3,93 & 3,23 & 3,96 & 2,92 & 4,14 & 3,28 & 5,58 & 4,15 \\
\hline & Máx. & 29,90 & 28,36 & 41,34 & 40,86 & 25,45 & 21,65 & 46,92 & 96,50 & 65,28 & 57,77 \\
\hline & $\Sigma$ & 4,62 & 3,09 & 5,76 & 3,75 & 3,85 & 2,17 & 4,48 & 3,34 & 5,77 & 3,96 \\
\hline \multirow{5}{*}{$\begin{array}{l}\text { Tempo } \\
\text { de } \\
\text { trabalho } \\
\text { (meses) }\end{array}$} & Mín. & 0,50 & 0,10 & 0,20 & - & 0,10 & 0,50 & - & 0,10 & - & - \\
\hline & Méd & 49,08 & 51,55 & 60,19 & 51,25 & 48,13 & 45,94 & 67,61 & 55,54 & 62,94 & 53,00 \\
\hline & Med & 27,75 & 30,75 & 32,10 & 30,90 & 30,70 & 33,90 & 36,15 & 34,35 & 32,10 & 30,20 \\
\hline & Máx. & 475,1 & 425,40 & 552,90 & 474,10 & 473,9 & 402,60 & 535,4 & 472,30 & 567,9 & 551,90 \\
\hline & $\sigma$ & 65,32 & 59,24 & 80,85 & 61,59 & 60,18 & 49,05 & 83,58 & 64,57 & 81,77 & 66,96 \\
\hline
\end{tabular}

Legenda: ${ }^{a}$ sexo masculino; b sexo feminino.

Fonte: Baseada nos Microdados RAIS (2014).

Tal cenário de desequilíbrio entre as remunerações também pode ser visualizado pela análise da mediana, na Tabela 4: as medianas da remuneração dos contadores de ambos os sexos estão abaixo da média, o que significa que metade dos profissionais percebem remuneração abaixo da média. Entretanto, ao se comparar média e mediada da remuneração de homens e mulheres, notase que as mulheres recebem contrapartida pelo seu trabalho ainda menor que os seus pares homens. Lehman (2012) reconhece tal fenômeno como feminização de profissões, em que a entrada de mulheres ou o domínio das mulheres em uma especialização muitas vezes sinaliza um declínio no status profissional, uma redução nos salários médios e outras marginalizações.

A análise do desvio padrão das remunerações de ambos os sexos, na Tabela 4, indica que a remuneração das contadoras mulheres varia menos em relação à remuneração percebida por contadores homens. Em outras palavras, essa baixa variabilidade reforça o cenário de remunerações inferiores para as mulheres na profissão contábil (Altoé, 2014; Brighenti, Jacomossi \& Silva, 2015).

Observa-se, ainda na Tabela 4, que apenas no Amazonas as mulheres possuem tempo de serviço médio superior ao dos homens; ressalta-se que a variável tempo de trabalho é mensal. Por outro lado, nota-se que em nenhum estado a diferença de tempo de trabalho médio superou um ano. Diante de uma diferença temporal relativamente pequena, percebe-se que a questão do tempo de trabalho realça a o aspecto da desigualdade salarial. No caso dos profissionais em análise, a diferença salarial não se deve à maior permanência em um mesmo emprego.

Embora não seja possível detalhar acerca de progressão e oportunidades de carreiras, pois os dados da pesquisa são oriundos de uma base sintética, percebe-se correspondência com os resultados do estudo de Brighenti, Jacomossi e Silva (2015). Os achados dos autores indicam um cenário semelhante com o desta pesquisa: remuneração superior para profissionais de contabilidade do sexo masculino em relação aos seus pares do sexo feminino, ainda que ambos atuassem em empresas de porte similar e tivessem tempo de trabalho e formação similares.

A Tabela 5 concentra as informações relativas à distribuição dos contadores por estado e cor de pele. As cores de pele estão representadas 
conforme a classificação que o Ministério do Trabalho e Emprego (MTE) definiu para a RAIS.

\section{Tabela 5}

Contadores por estado e cor de pele

\begin{tabular}{|c|c|c|c|c|c|c|c|c|c|c|}
\hline \multirow{2}{*}{ Cor da pele } & \multicolumn{2}{|c|}{ Amazonas } & \multicolumn{2}{|c|}{ Bahia } & \multicolumn{2}{|c|}{ Mato Grosso } & \multicolumn{2}{|c|}{ Paraná } & \multicolumn{2}{|c|}{ São Paulo } \\
\hline & $\mathbf{Q}$ & $\%$ & $\mathbf{Q}$ & $\%$ & $\mathbf{Q}$ & $\%$ & $\mathbf{Q}$ & $\%$ & $\mathbf{Q}$ & $\%$ \\
\hline 1. Indígena & 7 & 0,62 & 10 & 0,35 & - & - & 4 & 0,06 & 58 & 0,13 \\
\hline 2. Branca & 333 & 29,42 & 785 & 27,52 & 758 & 49,41 & 5.804 & 90,77 & 36.33 & 81,71 \\
\hline 4. Preta & 18 & 1,59 & 212 & 7,43 & 45 & 2,93 & 86 & 1,35 & 1.375 & 3,09 \\
\hline 6. Amarela & 24 & 2,12 & 32 & 1,12 & 17 & 1,11 & 95 & 1,49 & 895 & 2,01 \\
\hline 8. Parda & 750 & 66,25 & 1.813 & 63,57 & 714 & 46,54 & 405 & 6,33 & 5.802 & 13,05 \\
\hline Total & 1.13 & 100,0 & 2.852 & 100,0 & 1.534 & 100,0 & 6.394 & 100,0 & 44.46 & 100,0 \\
\hline
\end{tabular}

Fonte: Baseada nos Microdados RAIS (2014).

Os estados do Amazonas e da Bahia têm principalmente contadores que se declararam pardos. Já os estados do Paraná e de São Paulo, proporcionalmente, possuem principalmente contadores que se declararam brancos. Mato Grosso possui um relativo equilíbrio entre contadores que se declararam brancos e pardos.

A Tabela 6 mostra a classificação das empresas por porte, o qual foi definido pelo número de funcionários, conforme a classificação do MTE para a RAIS. Os microdados da RAIS fornecem informações individualizadas por trabalhador, deste modo a Tabela 6 pode ser lida da seguinte maneira, a título de exemplo, "na segunda linha, no Amazonas, existem 63 contadores que trabalham em empresas com até quatro funcionários".

\section{Tabela 6}

Porte das empresas por número de funcionários

\begin{tabular}{ccccccccccc}
\hline $\begin{array}{c}\text { Número de } \\
\text { funcionários }\end{array}$ & \multicolumn{2}{c}{ Amazonas } & \multicolumn{2}{c}{ Bahia } & \multicolumn{2}{c}{ Mato Grosso } & \multicolumn{2}{c}{ Paraná } & \multicolumn{2}{c}{ São Paulo } \\
\hline 0 & $\mathbf{Q}$ & $\%$ & $\mathbf{Q}$ & $\mathbf{\%}$ & $\mathbf{Q}$ & $\mathbf{\%}$ & $\mathbf{Q}$ & $\mathbf{\%}$ & $\mathbf{Q}$ & $\mathbf{\%}$ \\
\hline 0 & 9 & 0,80 & 43 & 1,51 & 15 & 0,98 & 85 & 1,33 & 522 & 1,17 \\
\hline até 4 & 63 & 5,57 & 231 & 8,10 & 160 & 10,43 & 428 & 6,69 & 1.566 & 3,52 \\
\hline de 5 a 9 & 74 & 6,54 & 233 & 8,17 & 149 & 9,71 & 488 & 7,63 & 1.875 & 4,22 \\
\hline de 10 a 19 & 86 & 7,60 & 256 & 8,97 & 163 & 10,63 & 558 & 8,73 & 2.741 & 6,16 \\
\hline de 20 a 49 & 139 & 12,28 & 384 & 13,46 & 253 & 16,49 & 905 & 14,15 & 5.059 & 11,38 \\
\hline de 50 a 99 & 119 & 10,51 & 317 & 11,11 & 184 & 11,99 & 668 & 10,45 & 5.250 & 11,81 \\
\hline de 100 a 249 & 218 & 19,26 & 365 & 12,79 & 253 & 16,49 & 1.165 & 18,22 & 8.466 & 19,04 \\
\hline de 250 a 499 & 176 & 15,55 & 370 & 12,97 & 210 & 13,69 & 829 & 12,97 & 6.260 & 14,08 \\
\hline de 500 a 999 & 174 & 15,37 & 314 & 11,01 & 96 & 6,26 & 592 & 9,26 & 4.854 & 10,92 \\
\hline 1000 ou mais & 74 & 6,54 & 340 & 11,92 & 51 & 3,32 & 676 & 10,57 & 7.869 & 17,70 \\
\hline Total & $\mathbf{1 . 1 3}$ & $\mathbf{1 0 0 , 0}$ & $\mathbf{2 . 8 5 3}$ & $\mathbf{1 0 0 , 0}$ & $\mathbf{1 . 5 3 4}$ & $\mathbf{1 0 0 , 0}$ & $\mathbf{6 . 3 9 4}$ & $\mathbf{1 0 0 , 0}$ & $\mathbf{4 4 . 4 6}$ & $\mathbf{1 0 0 , 0}$ \\
\hline
\end{tabular}

Fonte: Baseada nos Microdados RAIS (2014).

De modo geral, há uma homogeneidade relativa na distribuição de contadores, conforme o porte de seus locais de trabalho. A presença de tais profissionais em maior número, em termos percentuais, inicia-se em organizações que possuem de 20 a 49 funcionários. Entretanto, convém informar que as empresas com menor quantidade de funcionários podem ser empresas que 
prestam serviços contábeis a terceiros, ao passo que as empresas com mais de 1000 funcionários são menos numerosas que as demais.

\subsection{Análise do Modelo Econométrico e Comparação Salarial}

Considerando que a série de dados é cross-section não é de se esperar a autocorrelação residual, comum em séries temporais. De qualquer modo, foi feito o teste para a autocorrelação residual de primeira ordem (teste de DurbinWatson), não tendo sido detectado problema nos modelos.

Por outro lado, o problema de heterocedasticidade era esperado. Realizou-se o teste de White, e para os que apresentaram o problema de variância do erro não constante, utilizou-se o estimador consistente de White para desvio padrão e covariância. Não se detectou a presença de correlação significativa entre as variáveis explicativas. Considerando o número expressivo de observações em todos os modelos, tomou-se o pressuposto da normalidade, uma vez que não foi detectado o problema da autocorrelação residual e, que quando detectada violação do pressuposto de variância constante para os resíduos, utilizou-se de método de estimação da variância e covariância consistentes.

Em relação aos baixos valores dos coeficientes de determinação, eles não são relevantes, pois o $\mathrm{R}^{2}$ tem um papel muito modesto na análise de regressão. De acordo com Gujarati e Porter (2011), o R2 alto não representa evidência a favor do modelo e o $\mathrm{R}^{2}$ baixo não indica nenhuma evidência contrária a ele. Neste sentido, os autores ressaltam que a maior preocupação do pesquisador deve repousar na relevância lógica ou teórica das variáveis explicativas para a variável dependente e com seu significado estatístico.

Apresentam-se na Tabela 7 os resultados da regressão estimada para 0 Amazonas. O resultado do Teste $\mathrm{F}$ indica que o modelo de regressão estimado é estatisticamente significativo ao nível de confiança de $1 \%$. Observa-se que a média do salário dos contadores do estado do Amazonas é de $R \$ 4.835,13$, com um desvio padrão relativamente alto, de $R \$ 3.831,63$. Os itens que compõem essa remuneração são especificados na sequência. 
Tabela 7

Regressão estimada para o estado do Amazonas com Estimador Consistente de White

\begin{tabular}{|c|c|c|c|c|}
\hline Variável & Coeficiente & Erro-padrão & Estatística-t & Prob. \\
\hline $\mathrm{C}$ & $1.193,073$ & 287,2861 & 4,152910 & 0,0000 \\
\hline Tempo & 15,20321 & 2,233954 & 6,805516 & 0,0000 \\
\hline Tamanho & 422,1602 & 39,46260 & 10,69773 & 0,0000 \\
\hline Sexo & $1.465,163$ & 228,6807 & 6,407024 & 0,0000 \\
\hline cor_pele & $-710,8172$ & 238,5273 & $-2,980024$ & 0,0029 \\
\hline instrução2 & $1.816,097$ & 1187,509 & 1,529333 & 0,1265 \\
\hline instrução3 & $5.795,388$ & 2109,540 & 2,747229 & 0,0061 \\
\hline R-quadrado & 0,190319 & \multicolumn{2}{|c|}{$\begin{array}{l}\text { Média da variável } \\
\text { dependente }\end{array}$} & $4.835,137$ \\
\hline $\begin{array}{l}\text { R-quadrado } \\
\text { ajustado }\end{array}$ & 0,186000 & \multicolumn{2}{|c|}{$\begin{array}{l}\text { Desvio-padrão da variável } \\
\text { dependente }\end{array}$} & $3.831,632$ \\
\hline $\begin{array}{l}\text { Soma dos erros- } \\
\text { padrão da } \\
\text { regressão }\end{array}$ & $3.456,973$ & \multicolumn{2}{|c|}{ Estatística-f } & $1,34 \mathrm{E}+10$ \\
\hline $\begin{array}{l}\text { Soma dos } \\
\text { quadrados dos } \\
\text { resíduos }\end{array}$ & 0,000000 & \multicolumn{2}{|c|}{ Prob(Estatística-f) } & 44,07259 \\
\hline
\end{tabular}

Fonte: Elaborada pelos autores.

Uma das variáveis explicativas é o tempo de empresa, com coeficiente significativo ao nível de 1\%. Além disso, apresenta sinal coerente com a hipótese estabelecida, e informa que cada mês de trabalho representa um acréscimo médio de R\$15,20 ao salário médio. Nesta direção, o coeficiente associado à variável tamanho da organização também é significativo ao nível de $1 \%$ para a composição dos salários dos contadores amazonenses; a cada porte organizacional, ou seja, quanto maior for a empresa, acresce-se em média R\$ 422, 16 ao salário médio.

A Tabela 6 esclarece a classificação das empresas por porte, portanto permite a visualização do avanço da renda de cada pessoa conforme o tamanho da empresa.

Com relação à variável explicativa cor de pele, o Amazonas tem a particularidade de possuir o maior número de indivíduos que se declararam da cor parda dentre os estados que fazem parte do estudo, conforme apresentado na Tabela 5. O coeficiente desta variável é significativo ao nível de 1\%, mostrando que há discriminação em razão da cor da pele. O sinal negativo do coeficiente estimado para esta variável indica que os contadores que se declararam como pardos recebem em média $\mathrm{R} \$ 710,81$ a menos que os contadores não pardos. Este resultado sugere que, embora a maioria dos contadores amazonenses tenha se declarado como pardo, há discriminação racial, pois, os autodeclarados não pardos percebem remuneração maior.

O resultado do modelo mostra que existe discriminação em virtude do gênero. O coeficiente associado à variável sexo também passou pelo Teste T ao nível de $1 \%$ de significância, e mostrou-se relevante para a definição do salário médio. Os contadores amazonenses do sexo masculino possuem salário médio superior em relação ao das contadoras. Tal diferença média é de $R \$ 1.465,16$. Fica evidente a discriminação salarial em virtude de gênero, uma vez que o 
salário das mulheres é, em média, $\mathrm{R} \$ 3.369,97$, enquanto os homens recebem, em média, $R \$ 4.835,13$, remuneração quase um terço maior.

Em relação à variável grau de instrução, o título de mestre acrescenta à média da remuneração dos contadores amazonenses $R \$ 1.816,09$, tendo como referência os graduados. Ressalte-se, no entanto, que este coeficiente não se mostrou significativo para esta seleção de dados, apesar do sinal ter sido coerente. No caso do título de doutor, o coeficiente é estatisticamente significativo. Os contadores com esta titulação, independentemente do sexo, cor da pele e demais variáveis quantitativas, recebem em média $R \$ 5.795,38$ a mais que um contador apenas com graduação.

Para ilustrar a predição do salário para dos contadores do estado do Amazonas, é possível considerar os valores médios das variáveis quantitativas e prever o salário para contadores e contadoras, respectivamente. Considerandose apenas contadores com graduação, com média de tempo de trabalho de 49,08 meses, em uma empresa que está no estrato de porte de 100 a 249 funcionários, que tenham se autodeclarado não pardos, o salário médio esperado será de $R \$ 4.714,94$. Para os contadores que se declararam pardos $O$ salário médio estimado cai para $\mathrm{R} \$ 4.004,12$.

A mesma análise para o caso de uma contadora que tenha se declarado da cor não parda, o salário médio estimado será de $R \$ 3.249,78$. E, caso a contadora tenha se declarado como parda, o salário médio estimado é de $R \$$ 2.538,96. Assim, a diferença de salário médio estimado, considerando-se o mesmo nível de instrução (no caso graduação), o mesmo tempo de trabalho e porte de empresa entre um homem e uma mulher que se declararam da cor não parda é de $\mathrm{R} \$ 1.435,16$. Diante do o valor do salário mínimo nacional vigente (set. de 2016), esta diferença é de 1,63 salários mínimos, uma diferença salarial notável.

Os resultados obtidos para o estado da Bahia encontram-se na Tabela 8. 0 modelo passou pelo Teste F ao nível $1 \%$ de significância. Infere-se, portanto, que os contadores da Bahia possuem remuneração média de $\mathrm{R} \$ 4.391,69$. Os coeficientes associados às variáveis são significativos aos níveis de $1 \%$ e $5 \%$. Contudo, apenas a variável grau de instrução foi significativa a 10\%, fato esse que pode ser justificado pela quantidade reduzida de mestres, apenas 13 em um total de 2.852 profissionais. 
Tabela 8

Regressão estimada para o estado da Bahia com Estimador Consistente de White

\begin{tabular}{|c|c|c|c|c|}
\hline Variável & Coeficiente & Erro-padrão & Estatística-t & Prob. \\
\hline $\mathrm{C}$ & 350,1187 & 146,6261 & 2,387834 & 0,0170 \\
\hline tempo & 11,67875 & 0,956479 & 12,21015 & 0,0000 \\
\hline tamanho & 427,9436 & 20,84860 & 20,52625 & 0,0000 \\
\hline sexo & 818,7897 & 105,3341 & 7,773263 & 0,0000 \\
\hline cor_pele2 & $1.243,124$ & 137,8390 & 9,018661 & 0,0000 \\
\hline cor_pele3 & 682,1260 & 194,7801 & 3,502030 & 0,0005 \\
\hline instrução & 684,2369 & 1099,441 & 0,622350 & 0,5338 \\
\hline R-quadrado & 0,254842 & \multicolumn{2}{|c|}{$\begin{array}{l}\text { Média da variável } \\
\text { dependente }\end{array}$} & $4.391,694$ \\
\hline $\begin{array}{l}\text { R-quadrado } \\
\text { ajustado }\end{array}$ & 0,253212 & \multicolumn{2}{|c|}{$\begin{array}{l}\text { Desvio-padrão da variável } \\
\text { dependente }\end{array}$} & $3.170,006$ \\
\hline $\begin{array}{l}\text { Soma dos erros- } \\
\text { padrão da } \\
\text { regressão }\end{array}$ & $2.739,421$ & \multicolumn{2}{|c|}{ Estatística-f } & 156,3495 \\
\hline $\begin{array}{l}\text { Soma dos } \\
\text { quadrados dos } \\
\text { resíduos }\end{array}$ & $2,06 \mathrm{E}+10$ & \multicolumn{2}{|c|}{ Prob(Estatística-f) } & 0,000000 \\
\hline
\end{tabular}

Fonte: Elaborada pelos autores.

Os contadores do estado da Bahia possuem um acréscimo salarial de R $\$$ 11,67 médio a cada mês de trabalho completado na organização onde possuem vínculo empregatício. Ademais, a cada porte organizacional há um aumento de R\$ 427,94 na remuneração média.

A remuneração dos contadores que declararam a cor de pele como branca é, em média, $\mathrm{R} \$ 1.243,12$ superior em relação à remuneração média dos contadores de cor de pele parda, uma diferença de 22,06\%. Adicionalmente, os contadores que se declararam como indígenas, e cores de pele preta e amarela, percebem remuneração média $\mathrm{R} \$ 682,12$ superior aos contadores de pele parda. Novamente, os resultados revelam que existe discriminação racial de pardos em um estado que possui a maioria de contadores autodeclarados como tal.

O coeficiente associado à variável sexo também indica diferenças de remuneração que podem ser consideradas relevantes. Em média, as mulheres recebem $\mathrm{R} \$ 3.572,91$, uma diferença de 14,53\%, comparando-se aos contadores autodeclarados como brancos. Nota-se discriminação de gênero, pois mulheres pardas percebem, em média, até $36,59 \%$ a menos comparativamente à remuneração média de homens brancos.

Os resultados da regressão estimada para o Mato Grosso encontram-se na Tabela 9. O resultado do Teste $\mathrm{F}$ indica que o modelo de regressão estimado é estatisticamente significativo ao nível de confiança de $1 \%$. Constata-se que a média do salário contadores mato-grossenses é de $R \$ 4.192,45$, com um desvio padrão relativamente alto, $R \$ 3.790,59$. Todas as variáveis explicativas possuem coeficiente significativo a 1\%, exceto pelas variáveis cor_pele3 e instrução; ambas apresentaram coeficientes estatisticamente não significativos. 
Tabela 9

Regressão estimada para o estado de Mato Grosso

\begin{tabular}{ccccc}
\hline \multicolumn{1}{c}{ Variável } & Coeficiente & Erro-padrão & Estatística-t & Prob. \\
\hline C & $1.166,034$ & 203,5897 & 5,727371 & 0,0000 \\
\hline tempo & 9,516168 & 1,639086 & 5,805777 & 0,0000 \\
\hline tamanho & 360,5579 & 34,09558 & 10,57492 & 0,0000 \\
\hline sexo & $1.542,817$ & 153,3415 & 10,06131 & 0,0000 \\
\hline cor_pele2 & $-479,0178$ & 150,5118 & $-3,182594$ & 0,0015 \\
\hline cor_pele3 & $-313,4042$ & 458,0326 & $-0,684240$ & 0,4939 \\
\hline instrução & $1.346,607$ & 864,3105 & 1,558013 & 0,1194 \\
\hline R-quadrado & 0,105255 & $\begin{array}{l}\text { Média da variável } \\
\text { dependente }\end{array}$ \\
$\begin{array}{l}\text { R-quadrado } \\
\text { ajustado }\end{array}$ & 0,102331 & $\begin{array}{l}\text { Desvio-padrão da variável } \\
\text { dependente }\end{array}$ & $3.192,457$ \\
\hline $\begin{array}{l}\text { Soma dos erros- } \\
\text { padrão da } \\
\text { regressão }\end{array}$ & $3.591,418$ & Estatística-f & $3.790,599$ \\
\hline $\begin{array}{l}\text { Soma dos } \\
\text { quadrados dos } \\
\text { resíduos }\end{array}$ & $1,97 \mathrm{E}+10$ & Prob(Estatística-f) & 35,99676 \\
\hline
\end{tabular}

Fonte: Elaborada pelos autores.

Cada mês de trabalho em empresas mato-grossenses acrescenta ao salário médio o valor de $R \$ 9,52$. A cada porte organizacional, tem-se um acréscimo de $\mathrm{R} \$ 360,56$ ao salário médio total dos contadores. Além disso, os profissionais que declaram cor de pele branca possuem um salário médio superior em relação aos contadores que se declararam como não brancos. Embora, no Mato Grosso, haja equilíbrio entre a quantidade de profissionais brancos $(49,41 \%)$ e pardos $(46,54 \%)$, existe discriminação salarial por conta da cor de pele. Os contadores pardos recebem em média $\mathrm{R} \$ 479,02$ a menos que os contadores brancos.

A variável sexo configura-se como um dos principais fatores de diferenciação salarial no Mato Grosso. Em tal estado as contadoras recebem em média $\mathrm{R} \$ 2.580,53$ enquanto a remuneração média dos contadores homens é de $\mathrm{R} \$ 4.123,35$, o que representa $37,42 \%$ a menos na remuneração feminina. Tal fato caracteriza a discriminação do sexo feminino, dada a diferença de R\$1.542,82, superior a um terço, entre as remunerações de contadores e contadoras.

Apresenta-se na Tabela 10 os resultados da regressão estimada para o Estado do Paraná. Tal modelo de regressão mostrou-se estatisticamente significativo ao nível de $1 \%$ e todas os coeficientes das variáveis apresentaram sinais coerentes com as hipóteses estabelecidas. 
Tabela 10

Regressão estimada para o estado do Paraná com Estimador Consistente de White

\begin{tabular}{ccccc}
\hline Variável & Coeficiente & Erro-padrão & Estatística-t & Prob. \\
\hline C & 955,1308 & 490,8854 & 1,945731 & 0,0517 \\
\hline tempo & 13,84589 & 0,610259 & 22,68856 & 0,0000 \\
\hline tamanho & 471,7477 & 19,02528 & 24,79583 & 0,0000 \\
\hline sexo & $1.030,358$ & 90,94498 & 11,32946 & 0,0000 \\
\hline cor_pele & 482,6074 & 155,8847 & 3,095926 & 0,0020 \\
\hline instrução & $-978,2175$ & 451,2366 & $-2,167859$ & 0,0302 \\
\hline R-quadrado & 0,198786 & $\begin{array}{l}\text { Média da variável } \\
\text { dependente }\end{array}$ & $4.766,245$ \\
\hline $\begin{array}{l}\text { R-quadrado } \\
\text { ajustado }\end{array}$ & 0,198163 & $\begin{array}{l}\text { Desvio-padrão da variável } \\
\text { dependente }\end{array}$ & $4.027,060$ \\
\hline $\begin{array}{l}\text { Soma dos erros- } \\
\text { padrão da } \\
\text { regressão }\end{array}$ & $3.606,045$ & Estatística-f & 319,1637 \\
\hline $\begin{array}{l}\text { Soma dos } \\
\text { quadrados dos } \\
\text { resíduos }\end{array}$ & $8,36 \mathrm{E}+10$ & Prob(Estatística-f) & 0,000000 \\
\hline
\end{tabular}

Fonte: Elaborada pelos autores.

A média do salário dos contadores paranaenses é de $R \$ 4.766,25$, com um desvio padrão $\mathrm{R} \$ 4.027,06$, considerado relativamente alto. O coeficiente associado à variável tempo de serviço é significativo a 1\%; assim, a cada mês de trabalho tem-se um acréscimo médio de $\mathrm{R} \$ 13,85$ à remuneração. Outra variável relevante para explicar o salário é o tamanho ou porte da organização, também significativa ao nível de 1\%. A cada nível do porte das empresas acrescenta, em média, $\mathrm{R} \$ 471,75$ à remuneração dos contadores paranaenses.

A variável sexo também se mostrou significativa na composição da remuneração média dos contadores paranaenses a $1 \%$ de significância. Contadores do sexo masculino recebem, em média, $\mathrm{R} \$ 1.030,36$ a mais em relação às contadoras do sexo feminino, uma diferença de $21,63 \%$. Tal resultado confirma a hipótese inicial, em que se espera uma discriminação salarial em função de gênero para as contadoras mulheres, consoante aos estudos de Altoé (2014) e Brighenti, Jacomossi e Silva (2015).

A cor de pele mostrou-se um elemento altamente significativo, ao nível de $1 \%$, para a formação da remuneração média dos contadores paranaenses. Contadores que se declararam como de cor de pele branca possuem remuneração média superior de $\mathrm{R} \$ 482,61$ em relação aos contadores que declararam a cor de pele como não branca. Deste modo, confirma-se a hipótese estabelecida de que existe discriminação salarial em virtude da cor de pele, em conformidade com Duff (2011) e Thomson e Jones (2016).

A variável grau de instrução é estaticamente significativa a apenas a $10 \%$. Acredita-se que tal nível de significância é justificado pela parcela relativamente pequena de contadores mestres e doutores. Entretanto, percebe-se que contadores com maior formação têm um acréscimo médio de $R$ \$ 978,22 à sua remuneração.

Por fim, os resultados obtidos para SP estão dispostos na Tabela 11. Observase que a regressão estimada se mostrou estatisticamente significativa, passando 
pelo Teste F ao nível de significância de 1\%. Adicionalmente, todos os coeficientes associados às variáveis explicativas do modelo se mostraram estatisticamente significativas ao nível de 1\%. Com isso, é possível inferir que a remuneração média dos contadores do Estado de São Paulo é de R\$ 6.249,63.

Tabela 11

Regressão estimada para o estado de São Paulo com Estimador Consistente de White

\begin{tabular}{ccccc}
\hline \multicolumn{1}{c}{ Variável } & Coeficiente & Erro-padrão & Estatística-t & Prob. \\
\hline C & $1.914,397$ & 82,92688 & 23,08537 & 0,0000 \\
\hline tempo & 11,90015 & 0,378895 & 31,40748 & 0,0000 \\
\hline tamanho & 323,8471 & 9,503412 & 34,07694 & 0,0000 \\
\hline sexo & $1.801,391$ & 45,40801 & 39,67121 & 0,0000 \\
\hline cor_pele & 581,4965 & 54,89322 & 10,59323 & 0,0000 \\
\hline instrução & $1.977,484$ & 223,4700 & 8,848990 & 0,0000 \\
\hline \multicolumn{5}{l}{$\begin{array}{l}\text { Média da variável } \\
\text { dependente }\end{array}$} \\
\hline R-quadrado & 0,100790 & $\begin{array}{l}\text { Desvio-padrão da variável } \\
\text { dependente }\end{array}$ & $5.249,633$ \\
\hline $\begin{array}{l}\text { R-quadrado } \\
\text { ajustado }\end{array}$ & 0,100689 & Estatística-f \\
\hline $\begin{array}{l}\text { Soma dos erros- } \\
\text { padrão da } \\
\text { regressão }\end{array}$ & $4.765,562$ & Prob(Estatística-f) & 996,5928 \\
\hline $\begin{array}{l}\text { Soma dos } \\
\text { quadrados dos } \\
\text { resíduos }\end{array}$ & $1,01 \mathrm{E}+12$ & 0,000000 \\
\hline
\end{tabular}

Fonte: Elaborada pelos autores.

Cada mês trabalhado em suas respectivas empresas corresponde a R $\$$ 11,90 de acréscimo à remuneração média dos contadores paulistas. No que diz respeito ao tamanho da firma, cada porte da organização acresce $R \$ 323,84$ ao salário médio total. O grau de instrução também é fator determinante na composição salarial dos contadores: os profissionais mestres e doutores recebem em média $\mathrm{R} \$ 1.977,48$ a mais que os contadores apenas graduados.

Observa-se que contadores do sexo masculino recebem em média R $\$$ 1.801,39 a mais em relação as contadoras. Isto é, as contadoras paulistas recebem $28,82 \%$ a menos em relação aos homens, situação que caracteriza discriminação salarial em virtude de gênero. Adicionalmente, o coeficiente associado à variável cor de pele também é um fator determinante para a composição salarial. Indivíduos brancos, recebem em média $\mathrm{R} \$ 581,49$ a mais em relação aos indivíduos não brancos. Constata-se que a cor de pele se constitui como uma forma de diferenciação e discriminação salarial e corresponde a uma remuneração 9,30\% menor para contadores que se autodeclararam como não brancos.

Admite-se que as mulheres contadoras de cor de pele não branca, no estado de São Paulo, recebem, em média, $\mathrm{R} \$ 2.382,88$ a menos do que os homens brancos dessa mesma profissão. Isso caracteriza uma redução salarial total em virtude de gênero e cor de pele de $38,13 \%$. Deste modo, o salário médio desse grupo é de $R \$ 3.866,75$, enquanto que homens brancos recebem em média $R \$$ $6.249,63$. O desvio-padrão de $R \$ 5.025,26$ nas remunerações do estado de São Paulo corrobora as constatações acerca das diferenças salariais destacadas. 
A partir da análise dos resultados das regressões estimadas as hipóteses $\mathrm{H}_{1}$ e $\mathrm{H}_{2}$ foram aceitas, ao nível de significância de 1\%. Assim, nos cinco estados pesquisados, infere-se que i) os contadores do sexo masculino possuem chances maiores de receberem salários superiores em relação às contadoras $\left(\mathrm{H}_{1}\right)$; ii) existe discriminação salarial em função da cor de pele em favor dos sujeitos declarados como possuidores da cor de pele branca $\left(\mathrm{H}_{2}\right)$.

Os resultados obtidos pela modelagem econométrica encontram-se, em ordem decrescente, na Tabela 12. Independentemente do estado, os maiores salários foram recebidos por contadores do sexo masculino e de cor de pele branca. Assim, os dados salariais, obtidos da contabilidade, refletem as discriminações presentes na sociedade e em outras profissões (Loft, 1992). Também indicam uma hierarquia de gênero, dominada por homens brancos (Kirkham\& Loft, 1993). Esse grupo, também é responsável pelo desenvolvimento de discursos de gênero e estratégias de exclusão, a fim de garantir as suas posições privilegiadas (Lehman, 1992; Broadbent \& Kirkham, 2008).

\section{Tabela 12}

Salário Médio dos Contadores a partir dos modelos estimados

\begin{tabular}{lcccccccccc}
\hline & \multicolumn{2}{c}{ AM } & \multicolumn{2}{c}{ BA } & \multicolumn{2}{c}{ MT } & \multicolumn{2}{c}{ PR } & SP \\
\cline { 2 - 10 } “Grupo" & Salário $\begin{array}{c}\text { Redu } \\
\text { ção } \\
\%\end{array}$ & Salário & $\begin{array}{c}\text { Redu } \\
\text { ção }\end{array}$ & Salário & $\begin{array}{c}\text { Redu } \\
\text { ção } \\
\%\end{array}$ & $\begin{array}{c}\text { Salário } \\
\begin{array}{c}\text { Redu } \\
\text { çõo } \\
\%\end{array}\end{array}$ & $\begin{array}{c}\text { Salário } \\
\text { Redu } \\
\text { ção } \\
\%\end{array}$ \\
\hline $\begin{array}{l}\text { Homens } \\
\text { brancos }\end{array}$ & $4.835,1$ & & $5.634,81$ & & $4.123,35$ & $4.764,16$ & $6.249,63$ & \\
\hline $\begin{array}{l}\text { Homens } \\
\text { não } \\
\text { brancos }\end{array}$ & $4.124,3$ & 14,70 & $4.391,69$ & 22,06 & $3.644,33$ & 11,62 & $4.281,55$ & 10,13 & $5.668,13$ & 9,30 \\
\hline $\begin{array}{l}\text { Mulheres } \\
\text { brancas }\end{array}$ & $3.369,9$ & 30,30 & $4.816,02$ & 14,53 & $2.580,53$ & 37,42 & $3.733,80$ & 21,63 & $4.448,24$ & 28,82 \\
\hline $\begin{array}{l}\text { Mulheres } \\
\text { não } \\
\text { brancas }\end{array}$ & $2.659,2$ & 45,00 & $3.572,90$ & 36,59 & $2.101,51$ & 49,03 & $3.251,19$ & 31,76 & $3.866,74$ & 38,13 \\
\hline
\end{tabular}

Fonte: Elaborada pelos autores.

No contexto da população investigada, nota-se que gênero é mais discriminante do que a cor de pele. Dessa forma, a pirâmide de salarial da profissão é constituída pelos homens brancos no topo, seguidos pelos homens não brancos, mulheres brancas e mulheres não brancas na base. Resultado similar à hierarquia identificada pela pesquisa do IPEA (2015) e à realidade do meio profissional canadense (Thomson \& Jones, 2016).

\section{CONSIDERAÇÕES FINAIS}

Este artigo objetivou verificar a existência de discriminação por gênero e étnico-racial na remuneração de contadores, por região do país. Quanto ao primeiro objetivo específico, apesar da quantidade relativamente maior de contadoras mulheres, existe um equilíbrio entre a quantidade de profissionais de ambos os sexos biológicos, com exceção do Amazonas.

Em relação ao tempo de trabalho, somente no Amazonas as mulheres possuem tempo de serviço médio superior ao dos homens. Nos demais estados, os homens possuem maior tempo médio de serviço em relação às mulheres. Todavia, tal diferença é inferior a um ano em todos os estados. Deste modo, tal 
cenário descreve o distanciamento dos salários de homens e mulheres, uma vez que os resultados das regressões estimadas indicam que o tempo de serviço não é o principal fator de diferença salarial.

O segundo objetivo específico foi estimar, por meio de modelo econométrico, a composição salarial dos contadores. Em todos os estados, a maior remuneração média é de homens brancos. No Amazonas, Mato Grosso, Paraná e São Paulo, a segunda maior remuneração média pertence aos homens não brancos. Na sequência da escala da discriminação, nesses mesmos estados, têm-se a remuneração das contadoras mulheres brancas. Por último, as mulheres não brancas ocupam a menor remuneração média da classe contábil. A Bahia destaca-se como o único estado em que a discriminação por cor de pele foi superior à de gênero.

Para todos os estados, a discriminação por cor de pele e por gênero implicam, respectivamente, em uma redução remuneração média de $13,56 \%$ e 26,54\%. Logo, cor de pele e gênero resultam em uma redução de $40,10 \%$ da remuneração média dos contadores. Mediante tais resultados, confirma-se uma discriminação salarial em função de gênero para as mulheres, e em função de cor de pele para os contadores que se declararam não brancos.

Consequentemente, afirma-se que há discriminação salarial na classe profissional contábil. A maior discriminação relaciona-se ao gênero, seguida da discriminação racial, independente do estado, tamanho de empresa, tempo de trabalho e até mesmo escolaridade. É possível afirmar, ainda, que a população pesquisada se caracteriza por profissionais com ensino superior completo, fato que torna a discrepância salarial ainda mais evidente, visto que possuem o mesmo nível de formação.

A profissão contábil é uma classe profissional organizada e normatizada. Tal discriminação salarial trata-se de uma lacuna social a ser preenchida pela atuação dos órgãos representativos.

Essa realidade configura-se como um processo de exclusão. Analogamente à depreciação contábil, a depreciação salarial implica na redução do valor do ser humano que atua como contador. Assim, resultam na redução potencial de geração de benefícios econômicos presentes ou futuros dos profissionais discriminados.

Diante desse balanço salarial da profissão contábil, as contas gênero, etnia e raça possuem natureza devedora e os saldos dessas contas indicam um prejuízo acumulado. Tal resultado negativo é histórico e social, conforme destacado no referencial teórico. Cabe à classe contábil ajustar os efeitos desses eventos passados.

Sugerem-se para pesquisas futuras, pesquisas qualitativas a fim de identificar como a profissão contábil brasileira reproduz as desigualdades e/ou é produtora. O estudo das representações requer atenção aos símbolos, à linguagem, à retórica e às imagens nas organizações contábeis (Edgley, Sharma \& Anderson-Gough, 2016), que transmitem significados racializados de gênero e como essas representações ajudam não apenas a criar desigualdade e exclusão, mas a mantê-las. Além disso, considerar a compreensão da intersecção de identidades de gênero com outras identidades, como raça, etnia e até mesmo sexualidade 
Também, sugere-se para pesquisas futuras, análise das relações de poder nas quais o gênero e a raça estão inseridos (Kyriakidou, Kyriacou, Özbilgin \& Dedoulis, 2016) e investigação sobre a construção do gênero e raça e seus efeitos, através de estruturas e políticas de carreira, histórias de gênero, identidades, formas de incorporação de comportamentos, em uma variedade de contextos globais. No nível individual, também se sugere estudos sobre a experiência subjetiva de mulheres e homens sujeitos a construções sociais de gênero (Haynes, 2017).

\section{REFERÊNCIAS}

Acker, J. (1990). Hierarchies, jobs, bodies: A theory of gendered organizations. Gender \& society, 4(2), 139-158. DOI: https://doi.org/10.1177/089124390004002002

Altoé, S. M. L. (2014). Fatores explicativos do work-life balance de contadores à luz da psicologia positiva. (Dissertação de mestrado, Universidade Federal do Paraná, Curitiba, Paraná, Brasil). Recuperada de http://acervodigital.ufpr.br/handle/1884/36106

Annisette, M. (2003). The colour of accountancy: examining the salience of race in a professionalisation project. Accounting, Organizations and Society, 28(7), 639-674. DOI: https://doi.org/10.1016/S0361-3682(02)00030-2

Annisette, M., \& Prasad, A. (2016). Critical accounting research in hyper-racial times. Critical Perspectives on Accounting. DOl: https://doi.org/10.1016/j.cpa.2016.06.002

Bonilla-Silva, E. (1997). Rethinking racism: Toward a structural interpretation. American sociological review, 465-480. DOl: https://doi.org/10.1016/j.cpa.2016.06.002

Bonilla-Silva, E. (1999). The essential social fact of race. American Sociological Review, 64 (6), 899-906. DOI: https://doi.org/10.2307/2657410

Brighenti, J., Jacomossi, F., \& Silva, M. Z. (2015). Desigualdades de gênero na atuação de Contadores e Auditores no mercado de trabalho Catarinense. Enfoque Reflexão Contábil, 34 (2), 109-122. DOI: 10.4025/enfoque.v34i2.27807

Broadbent, J., \& Kirkham, L. (2008). Glass ceilings, glass cliffs or new worlds?. Accounting, Auditing \& Accountability Journal, 21 (4), 331-350. DOl: https://doi.org/10.1108/09513570810872888

Cambota, J. N., \& Pontes, P.A. (2007). Desigualdade de rendimentos por gênero intra-ocupações no Brasil, em 2004. Revista de Economia Contemporânea, 11 (2), 331- 350. DOI: https://doi.org/10.1590/S1415-98482007000200006 
Conceição, E. B. (2009). A negação da raça nos estudos organizacionais. Anais do Encontro Nacional da Asso ciação Nacional de Pós-Graduação e Pesquisa em Administração - Anpad, São Paulo, SP, Brasil, 33.

Duff, A. (2011). Big four accounting firms' annual reviews: A photo analysis of gender and race portrayals. Critical Perspectives on Accounting, 22(1), 20-38. DOI: https://doi.org/10.1016/j.cpa.2010.05.001

Edgley, C., Sharma, N., \& Anderson-Gough, F. (2016). Diversity and professionalism in the Big Four firms: Expectation, celebration and weapon in the battle for talent. Critical Perspectives on Accounting, 35, 13-34. DOl: https://doi.org/10.1016/j.cpa.2015.05.005

Fearfull, A., \& Kamenou, N. (2006). How do you account for it?: A critical exploration of career opportunities for and experiences of ethnic minority women. Critical Perspectives on Accounting, 17(7), 883-901. DOl: https://doi.org/10.1016/j.cpa.2005.08.006

Guimarães, N. A. (2002), "Os desafos da equidade: reestruturação e desigualdades de gênero e raça no Brasil". Cadernos Pagu, 17-18 (1), 237-266. DOl: http://dx.doi.org/10.1590/S0104-83332002000100009

Gujarati, D. N., \& Porter, D. C. (2011). Econometria Básica. Porto Alegre: AMGH Editora.

Hair, Jr., Babin, B., Money, A., \& Samouel, P. (2005). Fundamentos de métodos de pesquisa em administração. Porto Alegre: Bookman.

Hammond, T., Clayton, B. M., \& Arnold, P. J. (2012). An "unofficial" history of race relations in the South African accounting industry, 1968-2000: Perspectives of South Africa's first black chartered accountants. Critical Perspectives on Accounting, 23(4), 332-350. DOl: https://doi.org/10.1016/j.cpa.2011.10.005

Hammond, T. (2003). History from accounting's margins: international research on race and gender. Accounting History, 8(1), 9-24. DOl: https://doi.org/10.1177/103237320300800102

Hammond, T., \& Streeter, D. W. (1994). Overcoming barriers: early AfricanAmerican certified public accountants. Accounting, Organizations and Society, 19(3), 271-288. DOI: https://doi.org/10.1016/0361-3682(94)90035-3

Haynes, K. (2017). Accounting as gendering and gendered: A review of 25 years of critical accounting research on gender. Critical Perspectives on Accounting, 43, 110-124. DOl: https://doi.org/10.1016/j.cpa.2016.06.004

Haynes K. (2008). Moving the gender agenda or stirring chicken's entrails?: Where next for feminist methodologies in accounting? Accounting, Auditing \& Accountability Journal, $21(4), \quad 539-55 . \quad$ DOl: https://doi.org/10.1 108/09513570810872914 
Hirata, H. (2014). Gênero, classe e raça Interseccionalidade e consubstancialidade das relações sociais. Tempo social, 26(1), 61-73. DOI: https://doi.org/10.1590/S0103-20702014000100005

Instituto de Pesquisa Econômica Aplicada (2015). Retrato das Desigualdades de Gênero e Raça, 20 anos. Disponível em: http://www.ipea.gov.br/portal/images/stories/PDFs

/170306_retrato_das_desigualdades_de_genero_raca.pdf

Instituto de Pesquisa Econômica Aplicada (2009). Retrato das Desigualdades de Gênero e Raça - 1995 a 2015. Disponível em: http://www.ipea.gov.br/portal/images/stories/PDFs

/170306_apresentacao_retrato.pdf

Kim, S. N. (2004). Imperialism without empire: silence in contemporary accounting research on race/ethnicity. Critical Perspectives on Accounting, 15(1), 95-133. DOI: https://doi.org/10.1016/S1045-2354(03)00004-2

Kirkham, L. M., \& Loft, A. (1993). Gender and the construction of the professional accountant. Accounting, Organizations and Society, 18(6), 507-558. DOI: https://doi.org/10.1016/0361-3682(93)90002-N

Kyriakidou, O., Kyriacou, O., Özbilgin, M., \& Dedoulis, E. (2016). Equality, diversity and inclusion in accounting. Critical perspectives on accounting, 35, 1-12. DOI: https://doi.org/10.1016/j.cpa.2015.12.004

Lehman, C. R. (1992). "Herstory" in accounting: The first eighty years. Accounting, Organizations and Society, 17(3-4), 261-285. DOl: https://doi.org/10.1016/03613682(92)90024-M

Lehman, C. R. (2012). We've come a long way! Maybel! Re-imagining gender and accounting. Accountin, Auditing \& Accountability Journal, 25(2), 256-294. DOI: https://doi.org/10.1108/09513571211198764

Loft, A. (1992). Accountancy and the gendered division of labour: a review essay. Accounting, Organizations and Society, 17(3-4), 367-378. DOl: https://doi.org/10.1016/0361-3682(92)90029-R

Medeiros, C. R. O, \& Valadão Jr, V. M. (2011). Masculinidade e feminilidade na Ameas: holograma, ilhas de clareza ou uma selva desconhecida?. Cadernos EBAPE. 9(1), 79-96. DOI: http://dx.doi.org/10.1590/S1679-39512011000100006

Miller, P. (1994). Accounting as social and institutional practice: an introduction. In: A. G. Hopwood \& P. Miller (Eds.), Accounting as social and institutional practice (pp. 1-39). Grã-Bretanha: Cambridge University Press - Cambridge Studies in Management.

Nogueira, O. (2007). Preconceito racial de marca e preconceito racial de origem: sugestão de um quadro de referência para a interpretação do material sobre 
relações raciais no Brasil. Tempo social, 19(1), 287-308. DOl: https://doi.org/10.1590/\$0103-20702007000100015

Rosa, A. R. (2014). Relações Raciais e Estudos Organizacionais no Brasil/Race Relations and Organizational Studies in Brazil. Revista de Administração Contemporânea, 18(3), 240-260. DOl: http://dx.doi.org/10.1590/19827849rac20141085

Scott, J. W. (1995). Gênero: uma categoria útil de análise histórica. Educação \& Realidade, 20(2), 71-99.

Silva, S. M. C. D. (2016). Tetos de vitrais: gênero e raça na contabilidade no Brasil. (Tese de doutorado, Universidade de São Paulo, São Paulo, Brasil). Recuperada de http://www.teses.usp.br/teses/disponiveis/12/12136/tde03082016-111152/pt-br.php

Souza, E. M., \& Carrieri, A. P. (2010). A analítica Queer e seu rompimento com a concepção binária de gênero. Revista de Administração Mackenzie, 11 (3), 46-70. DOl: https://doi.org/10.1590/\$1678-69712010000300005

Steil, A. V. (1997). Organizações, gênero e posição hierárquica - compreendendo o fenômeno do teto de vidro. Revista de Administração, 32 (3), 62 -69.

Thomson, K., \& Jones, J. (2016). Colonials in camouflage: Metonymy, mimicry and the reproduction of the colonial order in the age of diversity. Critical Perspectives on Accounting, 35, 58-75. DOl: https://doi.org/10.1016/j.cpa.2015.05.001 


\section{CONTRIBUIÇÕES DOS AUTORES}

\begin{tabular}{|l|c|c|c|}
\hline \multicolumn{1}{|c|}{ Contribuição } & $\begin{array}{c}\text { José Luiz Borsatto } \\
\text { Junior }\end{array}$ & $\begin{array}{c}\text { Evellyn Danielly } \\
\text { Zabotti }\end{array}$ & $\begin{array}{c}\text { Maria da } \\
\text { Piedade Araújo }\end{array}$ \\
\hline $\begin{array}{l}\text { 1. Idealização e concepção do } \\
\text { assunto e tema da pesquisa }\end{array}$ & $\checkmark$ & $\checkmark$ & $\checkmark$ \\
\hline 2. Definição do problema de pesquisa & $\checkmark$ & $\checkmark$ & \\
\hline $\begin{array}{l}\text { 3. Desenvolvimento da Plataforma } \\
\text { Teórica }\end{array}$ & $\checkmark$ & $\checkmark$ & \\
\hline $\begin{array}{l}\text { 4. Delineamento da abordagem } \\
\text { metodológica da pesquisa }\end{array}$ & $\checkmark$ & $\checkmark$ & \\
\hline 5. Coleta de dados & $\checkmark$ & $\checkmark$ & $\checkmark$ \\
\hline $\begin{array}{l}\text { 6. Análises e interpretações dos dados } \\
\text { coletados }\end{array}$ & $\checkmark$ & $\checkmark$ & \\
\hline 7. Conclusões da pesquisa & $\checkmark$ & & \\
\hline 8. Revisão crítica do manuscrito & $\checkmark$ & & \\
\hline $\begin{array}{l}\text { 9. Redação final do manuscrito, } \\
\text { conforme as normas estabelecidas } \\
\text { pela Revista. }\end{array}$ & & & $\checkmark$ \\
\hline 10. Orientação & & & \\
\hline
\end{tabular}

